Journal of Bangladesh Academy of Sciences
Journal homepage: http://www.bas.org.bd/publications/jbas.html

Research Article

\title{
Chemical investigation on the male flowers of Carica Papaya using acid-base separation process
}

Md. Delwar Hossain*, Shamsun Naher, Mesbah Uddin Ahmad ${ }^{1}$ and Koushik Saha ${ }^{2}$

Department of Chemistry, Jagannath University, Dhaka, Bangladesh

\begin{tabular}{|c|c|}
\hline ARTICLE INFO & ABSTRACT \\
\hline $\begin{array}{l}\text { Article History } \\
\text { Received: } 22 \text { June } 2021 \\
\text { Revised: } 21 \text { November } 2021 \\
\text { Accepted: } 23 \text { November } 2021 \\
\text { Keywords: Carica Papaya, Male flowers, } \\
\text { Acid-base separation, Column Chromatography. }\end{array}$ & $\begin{array}{l}\text { Five long-chain hydrocarbons and a new brominated } \\
\text { nitrogenous terpenoid were isolated from the acidic } \\
\text { and basic fraction respectively of an ethanol extract } \\
\text { of the male flowers of Carica Papaya for the first } \\
\text { time. It was collected from Bangladesh Agriculture } \\
\text { Development Corporation, Gazipur. }\end{array}$ \\
\hline
\end{tabular}

\section{Introduction}

Carica Papaya is a small soft wooded, fast-growing tree with large glabrous palmatifid and palminerved leaves belonging to the family Caricaceae grows throughout Bangladesh. Locally it is known as papaya. C. Papaya has many medicinal properties (Vij and Prashar, 2015; Asghar et al. 2016). The ripe fruit is stomachic, appetizer, digestive, carminative. The milky juice of the unripe fruit is applied locally to the osuteri to procure abortion. The seeds are also said to be vermifuge, but they are mostly used as an emmenagogue. It is a popular belief that they may cause abortion. It has been reported that the seed extracts of C. Papaya have hypolipidaemic, anticancer, anti-inflammatory, and antifertility activities (Singh and Ali, 2011; Li et al., 2012; Julaeha et al., 2015). The root is ground up and mixed with water, and the resulting solution is used as an enema. The dry leaves, when placed in water, form yellowish-red liquor, which is drunk to cure stomach troubles.

Dengue fever treatment was carried out with $C$. Papaya leaves extracts (Ahmad et al., 2011). Tocopherol (Engel and de Vries, 1946) and Pseudocarpaine (Govindachari et al., 1954) were separated in the leaves of C. Papaya. Vitamin A,
Vitamin B, Vitamin C, volatile components, volatile acids, Aryl $\beta$-d-glucosides were identified in the fruits and vegetables (Miller, 1926; Flath and Forrey, 1977; Idstein et al., 1985; Schwab and Schreier, 1988). Glutamine, cyclotransfesase, papain were collected in the dried papaya latex (Messer and Ottesen, 1964). Benzyl isocyanate was found in the fruit pulp (Tang, 1971). Carpasemine, benzyl thiourea, benzyl isothiocyanate, hentriacontane, $\beta$-sitosterol, $\beta$-Dgalactosidase, $\alpha$-D-mannosidase, benzylglucosinolate, essential oils were isolated in the seeds (Panse and Paranjpe, 1943; Ettlinger and Hodgkins, 1956; Kimiko and Akira, 1983, Curl and Fenwick, 1983; He et al., 2017). Nonvolatile acids were collected in the plant (Brekke et al., 1971). Asparagines, histidine, arginine was extracted in the female flowers of C. Papaya. (Howard and Fenical, 1976; Ayyad et al., 1990).

Literature survey exhibits that few chemical investigations on the male flowers of the plant $C$. Papaya has been carried out. To the best of our knowledge, the only report on the male flowers of $C$. Papaya described the isolation of aspartic acid, $\beta$ sitosterol, long-chain hydroxyl ketone, and long-chain ester (Kasinathan et al., 1965; Mesbah et al., 2001). The present work was undertaken to carry out a systematic study on the male flowers of C. Papaya.

\footnotetext{
*Corresponding author: <delwar0171038512@yahoo.com>

${ }^{1}$ Department of Pharmacy, Gono University, Savar, Dhaka, Bangladesh

${ }^{2}$ Department of Chemistry, Jahangirnagar University, Savar, Dhaka, Bangladesh
} 


\section{Materials and Methods}

General: All reagents were used after distillation. Ethanol, chloroform, hexane, ethyl acetate, methanol were used as reaction solvents. Melting points were recorded by the thin disc method on a Fisher Johns electrothermal melting point apparatus. The IR spectra were taken on a Shimadzu FTIR- 8101 spectrophotometer as $\mathrm{KBr}$ disc and at times as thin film. ${ }^{1} \mathrm{H}-\mathrm{NMR}$ and ${ }^{13} \mathrm{C}$-NMR spectra were recorded as a solution in $\mathrm{CDCl}_{3}$ with TMS as the internal reference on an AC250 $\mathrm{MHz}$ digital NMR spectrophotometer at the chemistry department of the Universität Bayreuth, Bayreuth, Germany. Mass spectra (MS) were measured by a kratas MS-25 using DH.88 data system at the chemistry department of the Universität Hannover, Germany. Analytical thin-layer chromatography (TLC) was Merck aluminium oxide 60 F254 neutral or silica gel 60 F254 coated on 25 TCC aluminium sheets $(20 \times 20 \mathrm{~cm})$. Flash column chromatographic separations were performed on silica gel $60 \mathrm{~N}$ (neutral, $40-100 \mu \mathrm{M}$ ), or activated alumina oxide $(75 \mu \mathrm{M})$.

\section{Collection and Extraction of the Male Flowers of C. Papaya}

The male flowers of C. Papaya were supplied from the gardens under Bangladesh Agriculture Development Corporation at Kasimpur in Gazipur. The flowers were cleaned, and removed all impurities. The flowers $(1.6 \mathrm{~kg})$ were soaked with $5.0 \mathrm{~L}$ ethyl alcohol $(>98 \%)$ at room temperature for 24 hours. The extract was collected, and the process was repeated four more times. The extract was combined and evaporated to dryness by removal of the solvent, and a deep yellowish-red gummy crude Mass CP (45 g) was obtained.

\section{Acid-Base Separation of Mass CP}

Crude Mass CP (45 g) was treated with 5\% aqueous sulphuric acid $(50 \mathrm{~mL})$, and the acidic solution was then extracted by shaking with chloroform four times $(4 \times 50 \mathrm{~mL})$ in a separatory funnel. The chloroform extract was then dried over anhydrous $\mathrm{Na}_{2} \mathrm{SO}_{4}$ and subsequently evaporated to dryness on a rotary evaporator to yield a greenish-brown non-basic fraction $(2.5 \mathrm{~g})$. The residual aqueous acidic extract was made alkaline with 5\% sodium hydroxide solution to $\mathrm{pH} 12$ or above, and this was then extracted by shaking with chloroform in the usual way. The chloroform extract was dried over anhydrous sodium sulfate, and the solvent was removed at the pump below $40^{\circ} \mathrm{C}$ to give a reddishyellow basic fraction $(15 \mathrm{mg})$.

\section{Results and Discussion}

The macerated male flowers of Carica Papaya were exhaustively extracted with ethanol which gave a deep yellowish-red gummy product. The extract was separated into an acidic fraction and a basic fraction to isolate pure compounds.

The acidic fraction on column chromatographic separation gave one compound, which was shown by TLC and designated as compound $\mathbf{I}$. The basic fraction was found to be a mixture of at least two compounds, as shown by TLC. Column chromatography of the basic fraction was carried out and gave one pure compound, which was designated as compound 6 .

Acidic fraction gave one spot on TLC plate with $\mathrm{R}_{\mathrm{f}} 0.72$ in $\mathrm{n}$-hexane. It was presumed to be a pure compound I. It was a colorless gummy solid, melted at $51-52^{\circ} \mathrm{C}$. It was highly non-polar, as shown by its behavior on TLC plates. The IR spectrum (Fig. 1) of the compound showed absorption in the $2849 \mathrm{~cm}^{-1}$ region, owing to $\mathrm{Sp}^{3} \mathrm{C}$ $\mathrm{H}$ stretching vibrations and $\mathrm{C}-\mathrm{H}$ bending vibrations observed at 1464 and $1472 \mathrm{~cm}^{-1}$ region suggesting it to contain a long-chain alkyl group.

This was further confirmed by ${ }^{1} \mathrm{H}$ NMR (Fig. 2) of the compound, which showed a triple at $\delta 0.98$, a huge unsplit multiplate at $\delta 1.55$ for the methyl $\left(-\mathrm{CH}_{2}\right)$, methylene $\left(-\mathrm{CH}_{2}-\right)$ and methyne $(>\mathrm{CH}-)$ protons. ${ }^{13} \mathrm{C}$ NMR spectrum (Fig. 3) of the compound showed peaks between 14.106 to 31.937 , suggesting the presence of only an alkyl carbon atom in the compound. TLC behavior of compound I and the nature of its IR, ${ }^{1} \mathrm{H}$ NMR, and ${ }^{13} \mathrm{C}$ spectra suggested it to be a saturated hydrocarbon. 


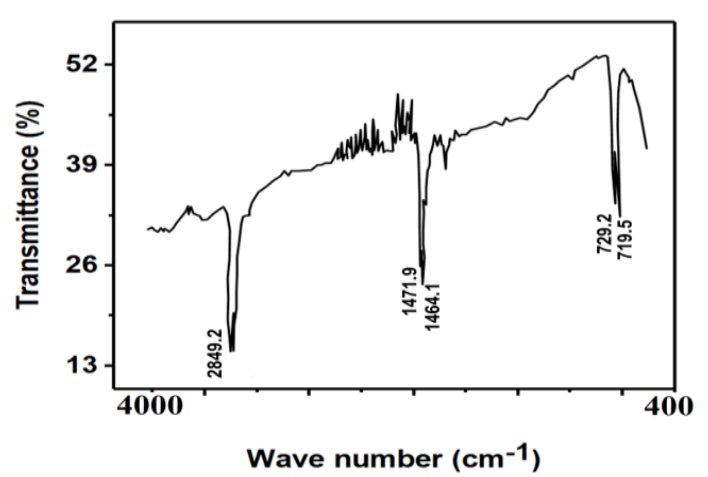

Fig. 1. IR spectrum of compound I

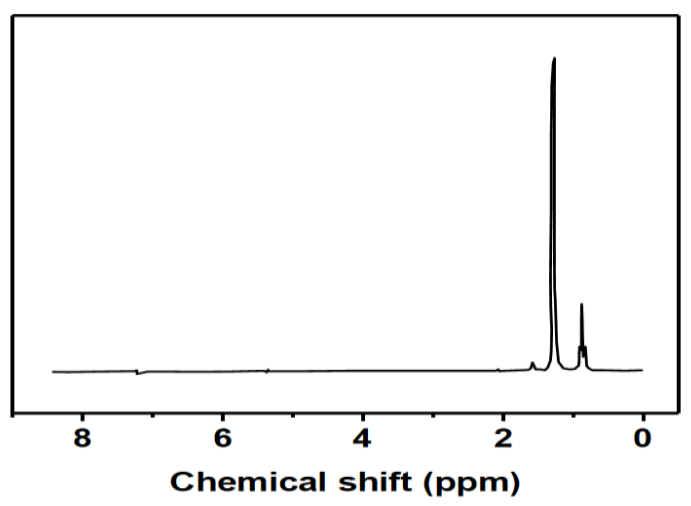

Fig. 2. ${ }^{1} \mathrm{H}$ NMR spectrum of compound I

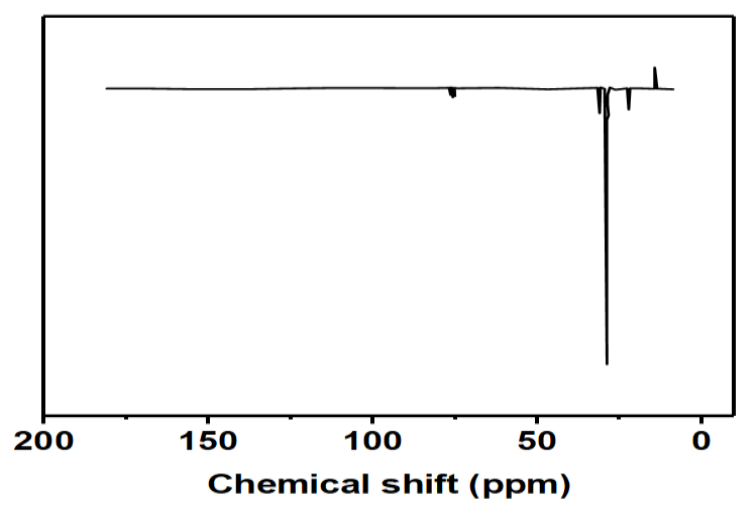

Fig. 3. ${ }^{13} \mathrm{C}$ NMR spectrum of compound I

Although the TLC of the compound suggested it to be a pure compound I, the GC-mass spectrum (Fig. 4) showed it to be a mixture of at least five compounds with scan nos. 41, 45, 47, 48, and 49.

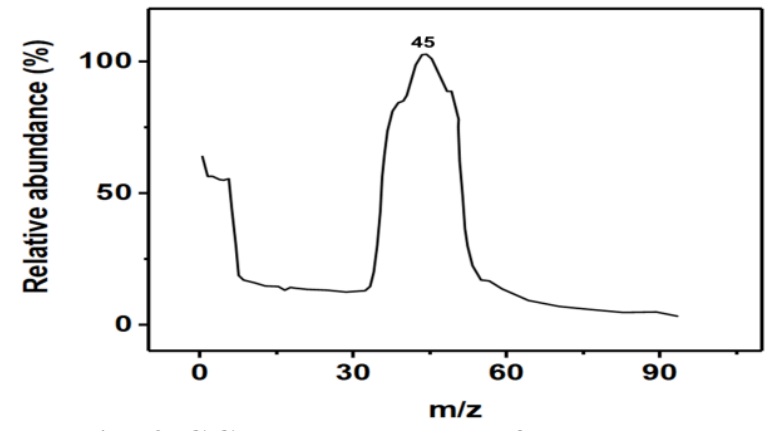

Fig. 4. GC-Mass spectrum of compound I

The mass spectrum corresponds to scan no. 41(Fig. 4a) showed the highest mass peak at $\mathrm{m} / \mathrm{z}$ 324. The mass fragments at $\mathrm{m} / \mathrm{z} 295,267,239,197,183,155,127,113$, 99, 85, 71, 57 (base peak), 43 with consecutive loss of 14 mass units and increasing intensity confirmed the presence of long alkyl chain in the compound. However, since the mass ion at $\mathrm{m} / \mathrm{z} 57$ is the base peak, it tends to support the presence of the 3-methyl propyl group at one end of the hydrocarbon chain. The hydrocarbon is therefore proposed to be (1).
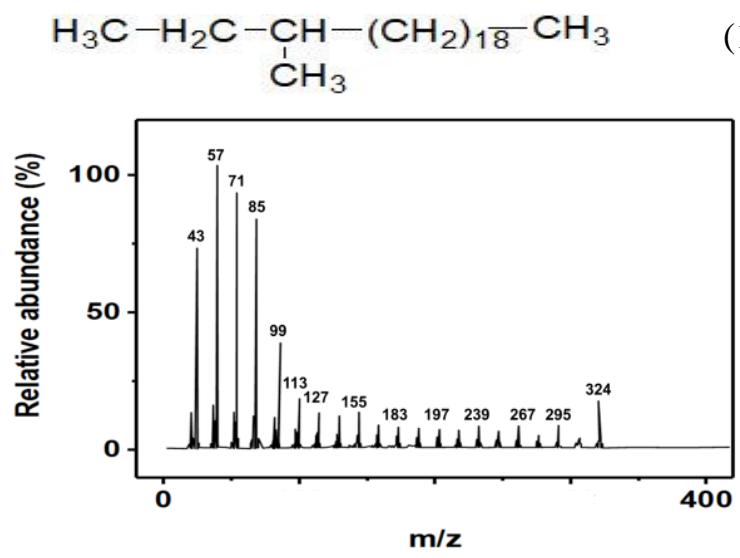

Fig. 4a. Mass spectrum of compound 1 corresponding to scan no. 41

The mass fragmentation pattern corresponds to scan no. 45 (Fig. 4b) showed the molecular ion peak at $\mathrm{m} / \mathrm{z}$ 352. It further showed the first mass fragment at $\mathrm{m} / \mathrm{z} 309$, indicating a loss of mass 43 (isopropyl unit) followed by successive loss of fourteen mass units. The molecular ion peak at $\mathrm{m} / \mathrm{z} 352$, base peak at $\mathrm{m} / \mathrm{z} 57$, and fragmentation pattern are consistent with that expected for a branched-chain hydrocarbon like (2). 


$$
\mathrm{H}_{3} \mathrm{C}-\mathrm{CH}_{2}-\underset{\mathrm{C}}{\mathrm{C}} \mathrm{H}-\left(\mathrm{H}_{3} \mathrm{CH}_{2}\right)_{18} \underset{\stackrel{\mathrm{C}}{\mathrm{C}} \mathrm{H}}{\mathrm{C}}-\mathrm{CH}_{3}
$$

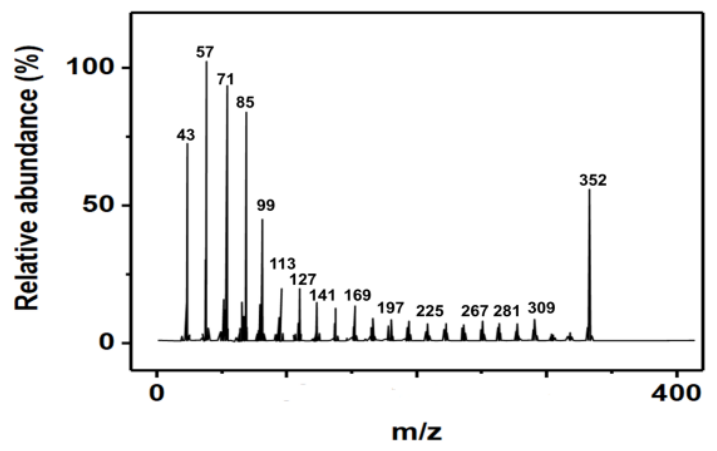

Fig. 4b. Mass spectrum of compound 2 corresponding to scan no. 45

The mass spectrum of the compound corresponding to scan no. 47 (Fig. 4c) showed the highest mass peak at $\mathrm{m} / \mathrm{z} 380$. The mass fragments also showed mass ions at $\mathrm{m} / \mathrm{z}$ 295, 267, 239, 197, 183, 155, 127, 113, 99, 85, 71, 57 (base peak), 43. It is clearly seen that the molecular ion peak is at $\mathrm{m} / \mathrm{z} 380$, and the first mass ion fragment at 295 , indicating a loss of 85 , is followed by successive loss of fourteen mass units. The molecular ion peak at $\mathrm{m} / \mathrm{z} 380$, base peak at $\mathrm{m} / \mathrm{z} 57$, and fragmentation pattern can be readily explained if the hydrocarbon has the following structure (3).
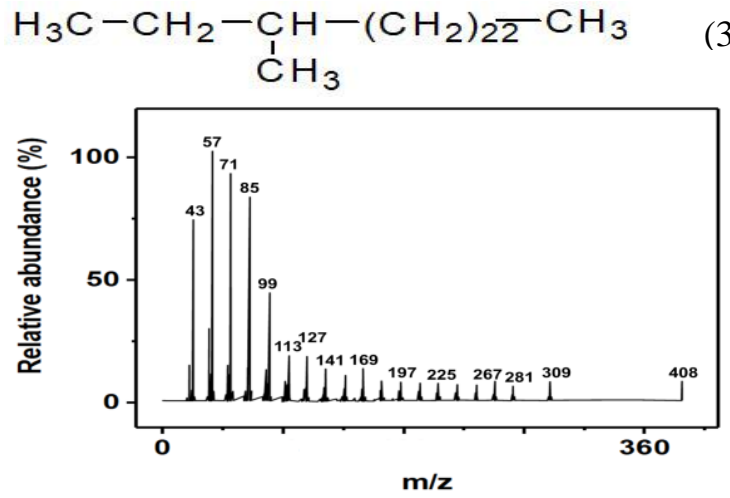

Fig. 4c. Mass spectrum of compound 3 corresponding to scan no. 47

Similar analysis of the mass spectrum corresponding to scan no. 48 (Fig. 4d) with molecular ion at $\mathrm{m} / \mathrm{z} 408$ suggest the hydrocarbon to have the structure (4).

$$
\mathrm{H}_{3} \mathrm{C}-\mathrm{CH}_{2}-\underset{\mathrm{C}}{\mathrm{C}} \mathrm{H}_{3}-\left(\mathrm{CH}_{2}\right)_{24}-\mathrm{CH}_{3}
$$

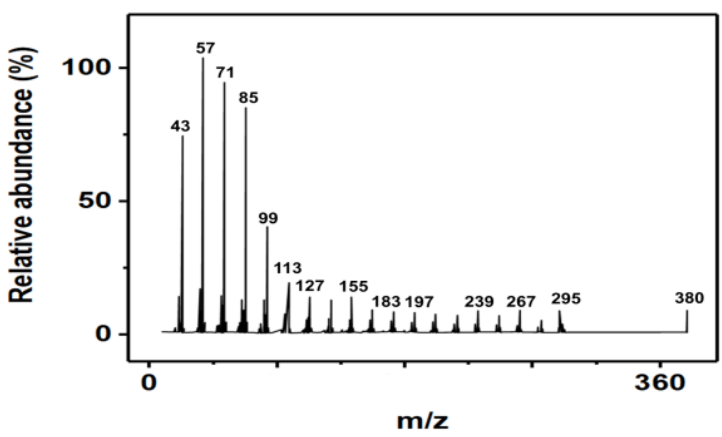

Fig. 4d. Mass spectrum of compound 4 corresponding to scan no. 48

The analysis of the mass spectrum of the compound corresponding to scan no. 49 (Fig. 4e) showed the molecular ion peak at $\mathrm{m} / \mathrm{z} 436$, a base peak at $\mathrm{m} / \mathrm{z} 57$, and the first mass fragment from molecular ion at $\mathrm{m} / \mathrm{z}$ 393, indicating a loss of isopropyl group. These observations can be rationalized in the hydrocarbon has the structure (5).
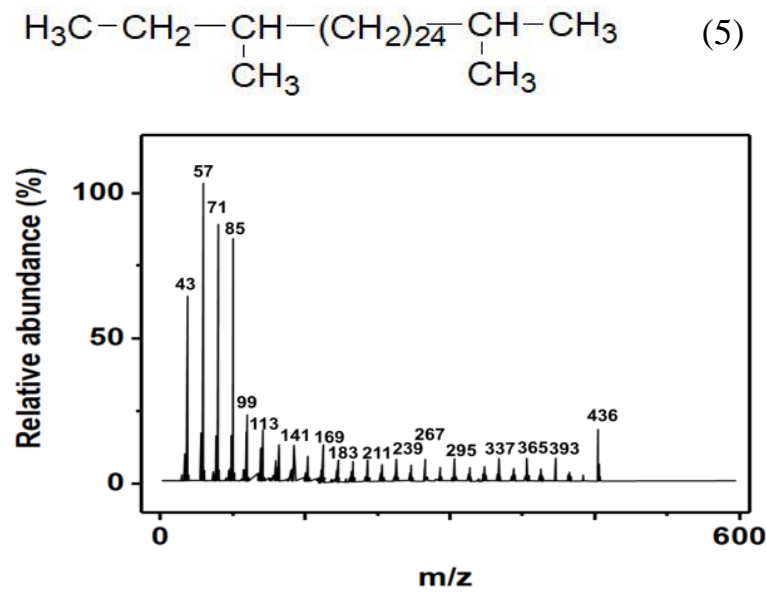

Fig. 4e. Mass spectrum of compound 5 corresponding to scan no. 49

The basic fraction showed two spots on TLC plates in different solvent systems and had Rf $0.74,0.53$ in EtOAc: $\mathrm{MeOH}$ (19:1) with tailing from the baseline. A compound $6(2 \mathrm{mg})$ in the pure state was isolated by column chromatography and gave one spot at Rf 0.54 in EtOAc:MeOH (19:1). Compound 6 was a brown colored gummy substance, and it was soluble in chloroform, ethyl acetate, and methanol. 
The compound's IR spectrum (Fig. 5) showed two bands at 3308 and $3200 \mathrm{~cm}^{-1}$ for unsymmetrical and symmetrical N-H stretching vibration, respectively, of a primary amino group. The band at $1620 \mathrm{~cm}^{-1}$ could be ascribed to $\mathrm{N}-\mathrm{H}$ bending. The absorption at $2926 \mathrm{~cm}^{-1}$ suggested the compound to contain $\mathrm{C}-\mathrm{H}$ stretching vibration of olefinic or aromatic type. The band at $1666 \mathrm{~cm}^{-1}$ confirmed the presence of $\mathrm{C}=\mathrm{C}$. The proton NMR spectrum (Fig. 6) of the compound showed a doublet at $\delta 0.85$, an unsplit singlet at $\delta 1.23$, and multiplet at $\delta 1.5$ for the methyl, methylene and methyne type protons, respectively. In contrast, protons of the amino group $\left(-\mathrm{NH}_{2}\right)$ appeared as a broad doublet at $\delta$ 2.0. The absorption in the region at $\delta$ 5.3-5.7 indicated the presence of several olefinic protons, which could not be quantified because of broad absorption.

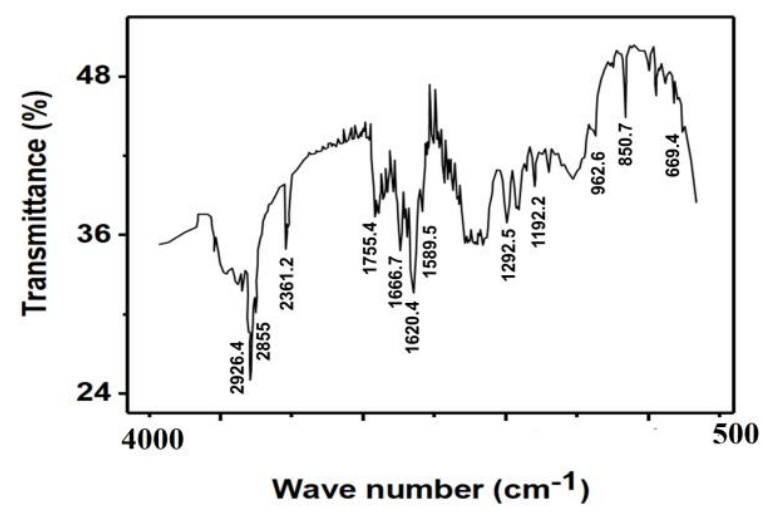

Fig. 5. IR spectrum of compound 6

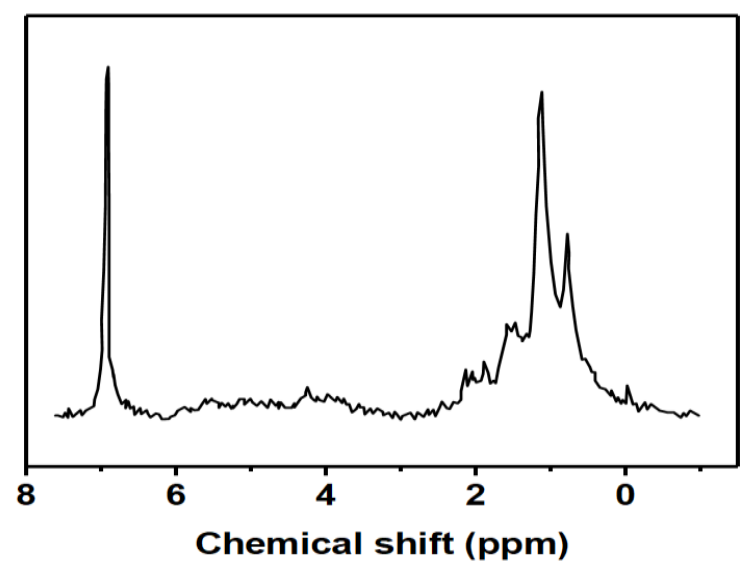

Fig. 6. ${ }^{1} \mathrm{H}$ NMR spectrum of compound 6

The compound's mass spectrum (Fig. 7) showed two mass peaks at $\mathrm{m} / \mathrm{z} 396 / 398$ (1:1), suggesting the presence of a bromine atom in the molecule. The base peak was observed at $\mathrm{m} / \mathrm{z} 326 / 328$ and other peaks at $353 / 355,286 / 288,242 / 244$ in the ratio $1: 1$ showed the attachment of the bromine atom with the corresponding fragment.

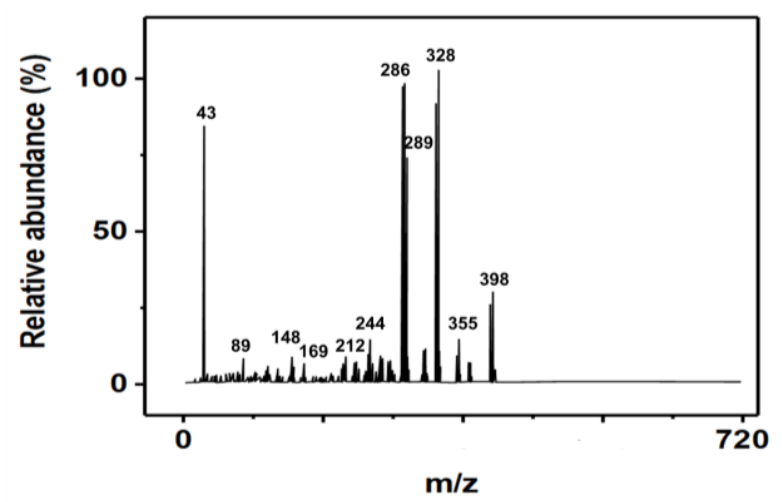

Fig.7. Mass spectrum of compound 6

If the highest mass ion at $\mathrm{m} / \mathrm{z} 396 / 398$ of the compound is considered as the molecular ion peak, various combinations of $\mathrm{C}, \mathrm{H}, \mathrm{N}, \mathrm{Br}$ to fit in the molecular weight leads to the molecular formula $\mathrm{C}_{21} \mathrm{H}_{37} \mathrm{~N}_{2} \mathrm{Br}$ during this workout attention was, however, given to the biogenetic route to terpenoid compounds. The exercise led to the following structure (6).

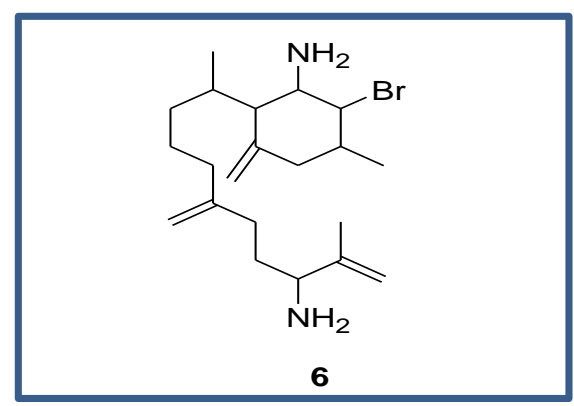

\section{Conclusions}

Ethanol extract of male flowers was separated into an acidic and basic fraction with $5 \%$ aqueous sulphuric acid and 5\% sodium hydroxide solution, respectively. The acidic fraction gave long-chain hydrocarbons. The GC Mass spectrum indicated a mixture of five compounds $1,2,3,4$, and 5 . The basic fraction yielded bromine substituted terpenoid compound, 6 . The structure of the compounds was elucidated by spectroscopic analysis, e.g., IR, NMR, and Mass.

\section{Acknowledgement}

We thank Jagannath University, Dhaka, Bangladesh, for financial support. 


\section{Conflicts of Interest}

The authors declare that they have no conflicts of interest regarding the publication of this article.

\section{References}

Ahmad N, Fazal H, Ayaz $M$ and Abbasi BH, Mohammad I, Fazal L. Dengue fever treatment with Carica Papaya leaves extracts. Asian Pac. J. Trop. Biomed. 2011; 1(4): 330-333.

Asghar N, Naqvi SAR, Hussain Z, Rasool N, Khan ZA, Shahzad SA, Sherazi TA and Janjua MRSA. Compositional difference in antioxidant and antibacterial activity of all parts of the Carica Papaya using different solvents. Chem. Cent. J. 2016; 10: 1-11.

Ayyad SEN, Dawidar AM, Dias HW, Howie RA, Jakupovic $\mathrm{J}$ and Thomson RH. Three halogenated metabolites from Laurencia obtuse. Phytochemistry 1990; 29: 3193-3196.

Brekke JE, Chan HT, Chang TSK and Stafford AE. Nonvolatile acids of papaya. J. Agr. Food Chem. 1971; 19(2): 263-265.

Curl CL and Fenwick GR. On the determination of papaya seed adulteration of black pepper. Food Chem. 1983; 12(4): 241-247.

Engel $\mathrm{C}$ and de Vries AM. The tocopherol (vitamine E) contents of differed foods from the Dutch East Indies. Z. Vitam. Forsch. 1946; 18: 89-90.

Ettlinger GM and Hodgkins JE. The mustard oil of papaya seed. J. Org. Chem. 1956; 21(2): 204-205.

Flath RA and Forrey RR. Volatile components of papaya (Carica Papaya L., Solo variety). J. Agric. Food Chem. 1977; 25(1): 103-109.

Govindachari TR, Pai BR and Narasimhan NS. Pseudocarpaine, a new alkaloid from Carica Papaya L. J. Chem. Soc.1954; 1847-1849.

He X, Ma Y, Yi G, Wu J, Zhou L and Guo H. Chemical composition and antifungal activity of Carica Papaya Linn. seed essential oil against Candida spp. Lett. Appl. Microbiol. 2017; 64: 350-354.

Howard BM and Fenical W. $\alpha$ - and $\beta$-snyderol; new bromo-monocyclic sesquiterpenes from the seaweed Laurencia. Tetrahedron Lett. 1976; 17(1): 41-44.
Idstein $\mathrm{H}$, Bauer $\mathrm{C}$ and Schreier P. Volatile acids in tropical fruits: cherimoya (Annona cherimolia, Mill.), guava (Psidium guajava, L.), mango (Mangifera indica, L., var. Alphonso), papaya (Carica Papaya, L.). Z. Lebensm. Unters. Forsch 1985; 180(5): 394-397.

Julaeha E, Permatasari Y, Mayanti T and Diantini A. Antifertility compound from the seeds of Carica Papaya. Procedia Chem. 2015; 17: 66-69.

Kasinathan S, Ramakrishnan S and Srinivasan B. Amino-acids of male and female flowers of Papaya. Current Sci. (India). 1965; 34(7): 211.

Kimiko $\mathrm{O}$ and Akira M. Purification and characterization of $\beta$-D-galactosidase and $\alpha$-Dmannosidase from papaya (Carica papaya) seeds. Agric. Biol. Chem. 1983; 47(11): 2441-2451.

Li ZY, Wang Y, Shen WT and Zhou P. Content determination of benzyl glucosinolate and anticancer activity of its hydrolysis product in Carica papaya L. Asian Pac. J. Trop. Med. 2012; 3: 231-233

Mesbah UA, Saha K and Hossain MD. Chemical constituents of male flower of Carica Papaya. J. Bangladesh Chem. Soc. 2001; 14(1): 91-94.

Messer M and Ottesen M. Isolation and properties of glutamine cyclotransferase of dried papaya latex. Biochim. Biophys. Acta. 1964; 92: 409-411.

Miller CD. The vitamins (A, B, and C) of papaya. Biochem. J. 1926; 20(3): 515-518.

Panse TB and Paranjpe AS. A study of 'Carpasemne' isolated from Carica Papaya seeds. Proc. Indian Acad. Sci. 1943: 18(3): 140-144.

Schwab W and Schreier P. Aryl $\beta$-D-glucosides from Carica Papaya fruit. Phytochemistry. 1988; 27(6): 1813-1816

Singh O and Ali M. Phytochemical and antifungal profiles of the seeds of Carica Papaya L. Indian J. Pharm. Sci. 2011; 4: 447-451.

Tang CS. Benzyl isothiocyanate of papaya fruit. Phytochemistry 1971; 10(1): 117-121.

Vij $\mathrm{T}$ and Prashar Y. A review on medicinal properties of Carica Papaya Linn. Asian Pac. J. Trop. Dis. 2015; 5(1): 1-6. 